Ciência Florestal, Santa Maria, v. 22, n. 3, p. 625-630, jul.-set., 2012

ISSN 0103-9954

\title{
IDENTIFICAÇÃO DE SUBSTRATO ADEQUADO PARA GERMINAÇÃO DE SEMENTES DE Allophylus edulis (A. St.-Hil., A. Juss. \& Cambess.) Radlk.
}

\author{
IDENTIFICATION OF SUITABLE SUBSTRATE FOR SEEDS GERMINATION OF \\ Allophylus edulis (A. St.-Hil., A. Juss. \& Cambess.) Radlk. \\ Ezequiel Gasparin ${ }^{1}$ Maristela Machado Araujo ${ }^{2}$ \\ Angela Luciana de Avila ${ }^{3}$ Angélica Polenz Wielewicki ${ }^{4}$
}

\begin{abstract}
RESUMO
Este trabalho objetivou identificar a melhor metodologia que expressasse a germinação e a qualidade das sementes de Allophylus edulis, analisando diferentes substratos. Inicialmente, realizou-se a caracterização do lote através de Peso de Mil Sementes (PMS), Teor de Água (TA) e Condutividade Elétrica (CE). No Teste de Germinação foram avaliados os seguintes tratamentos (substratos): sobre papel mata-borão (PMB), sobre papel filtro (SPF), sobre (SA) e entre areia (EA), sobre (SV) e entre vermiculita (EV) e rolo de papel (RP), sendo conduzidos em câmara de germinação Mangelsdorf $\left(25^{\circ} \mathrm{C}\right)$. Os dados foram expressos em percentagem de plântulas normais, anormais, sementes mortas e firmes e ainda, avaliado o índice de velocidade de germinação. Foi utilizado o delineamento inteiramente casualizado com quatro repetições por tratamento. Os substratos sobre areia (SA) e entre vermiculita (EV) foram os mais adequados para o teste de germinação, sendo que a primeira contagem de plântulas normais pôde ser feita entre 12 e 15 dias e a final aos 24 dias após a semeadura.
\end{abstract}

Palavras-chave: análise de sementes; substrato; espécie nativa; vacum.

\begin{abstract}
This study investigated the methodology that best expresses the germination and quality of Allophylus edulis seeds, analyzing different substrates. Initially, there was the characterization of the batch by Weight of Thousand Seeds (PMS), Water Content (TA) and Electrical Conductivity (CE). In the Germination Test were evaluated the following treatments (substrates): on blotting paper (PMB), on filter paper (SPF) on (SA) and among sand (EA), on (SV) and among vermiculite (EV) and paper roll (RP), being conducted in a germination chamber Mangelsdorf $\left(25^{\circ} \mathrm{C}\right)$. Data were expressed in percentages of normal and abnormal seedlings, dead seeds and firm and also, it was assessed the speed of germination index. It was used a completely randomized design with four replicates per treatment. The substrates among sand (SA) and among vermiculite (EV) were the most suitable for the germination test and the first count of normal seedlings can be made between 12 and 15 days and the final 24 days after sowing.
\end{abstract}

Keywords: seeds test; substrate; native species; vacuum.

1. Engenheiro Florestal, Msc., Programa de Pós-graduação em Engenharia Florestal, Centro de Ciências Rurais, Universidade Federal de Santa Maria, Av. Roraima, 1000, CEP 97105-900, Santa Maria (RS). ezequiel_gasparin@hotmail.com

2. Engenheira Florestal, Dra ${ }^{\text {a }}$, Professora Adjunta do Departamento de Ciências Florestais, Centro de Ciências Rurais, Universidade Federal de Santa Maria, Av. Roraima, 1000, CEP 97105-900, Santa Maria (RS). araujo.maristela@gmail.com

3. Engenheira Florestal, Msc., Professora da Universidade do Oeste de Santa Catarina, Rua Dirceu Giordani, 696, Bairro Jardim Universitário, CEP 89820-000, Xanxerê (SC). angeladeavila@gmail.com

4. Engenheira Agrônoma, Dra $^{\mathrm{a}}$, Fiscal Federal Agropecuário, Pesquisadora do Ministério da Agricultura, Av. Farrapos, 285, CEP 90220-044. Porto Alegre (RS). angelica.polenz@agricultura.gov.br

Recebido para publicação em 19/04/2010 e aceito em 09/06/2011

Ci. Fl., v. 22, n. 3, jul.-set., 2012 


\section{INTRODUÇÃO}

Allophylus edulis (A. St.-Hill., Cambess. \& A. Juss.) Radlk pertence à família Sapindaceae, sendo conhecida popularmente como vacum, chal-chal, baga-de-morcego, entre outros e ocorre naturalmente desde o Maranhão (MA) até o Rio Grande do Sul (RS) (LONGHI, 1995; CARVALHO, 2006). A madeira é adequada para marcenaria, moirões, lenha e carvão, indicada para arborização de praças e avenidas, sendo considerada ótima espécie para restauração de ambientes ripários. É uma espécie descrita como esciófita, pioneira ou secundária inicial, com florescimento durante os meses de setembro a novembro e frutificação de outubro a novembro. As sementes possuem comportamento recalcitrante perdendo o poder germinativo rapidamente (BACKES e NARDINO, 1998; LORENZI, 1998; CARVALHO 2006).

Estudos relacionados ao comportamento silvicultural de espécies florestais nativas são incipientes e de relevante importância para o sucesso de projetos de reflorestamento para fins comerciais ou de recuperação ambiental (CUNHA et al., 2005). $\mathrm{O}$ conhecimento sobre o processo germinativo de sementes florestais é fundamental para propor metodologias de análise de sementes com a finalidade de propiciar um controle mais rígido na comercialização e na qualidade da produção de sementes e mudas florestais. Segundo Copeland e McDonald (1995), através do teste de germinação é possível avaliar o potencial germinativo e a viabilidade de sementes sob condições favoráveis, permitindo comparar e determinar a qualidade do lote de sementes, o potencial de armazenamento e obter informações requeridas para certificação e garantia para padronização na comercialização do lote de sementes.

A germinação botânica considera o rompimento do tegumento da semente pela radícula. Porém, na análise de sementes esta é considerada germinada a partir do momento em que as plântulas apresentam as suas estruturas essenciais, caracterizadas como normais, o que permite garantir a sobrevivência em condições de campo (LABOURIAU, 1983).

A semeadura em substrato úmido tem o objetivo de fornecer uma quantidade de água suficiente para a germinação das sementes. Quando as mesmas estiverem germinadas, os diferentes substratos promovem o suporte para as plântulas (SCHMIDT, 2007). A escolha do tipo de substrato a ser utilizado deve levar em consideração o tamanho da semente, sua exigência quanto à quantidade de água, sensibilidade ou não à luz e facilidade que o mesmo proporciona para o desenvolvimento e avaliação das plântulas (BRASIL, 2009). O excesso ou a falta de água no substrato podem ser prejudiciais à germinação, interferindo nos resultados (OLIVEIRA, 2007).

Diferentes substratos podem ser utilizados no teste de germinação, dentre os quais estão: papeltoalha, papel-filtro, papel mata-borrão, terra, areia e vermiculita. Os dois últimos representam uma boa opção a ser utilizada como substrato na germinação de sementes florestais, devido à baixa contaminação por micro-organismos que ocorre com seu uso. A vermiculita é indicada para sementes grandes e esféricas, permitindo maior contato do substrato com a semente. Para sementes de tamanho pequeno a médio e de forma achatada, o uso do papel é mais adequado (FIGLIOLIA et al., 1993).

Assim, visando contribuir para a definição de métodos para análise de sementes florestais nativas, este trabalho objetivou identificar o substrato adequado para a realização do teste de germinação de sementes de Allophylus edulis.

\section{MATERIAL E MÉTODOS}

O trabalho foi conduzido no Laboratório de Sementes (Viveiro Florestal) do Departamento de Ciências Florestais, Universidade Federal de Santa Maria (UFSM). No estudo foram utilizadas sementes de Allophylus edulis coletadas de cinco árvores, localizadas em remanescentes florestais na localidade de Val Feltrina, município de Silveira Martins, RS, no dia 05 de novembro de 2008. Após a coleta, o material foi transportado até o laboratório onde ocorreu o beneficiamento dos frutos.

O despolpamento foi realizado de forma manual, após os frutos permanecerem submersos em água por, aproximadamente, duas horas. Depois da remoção da polpa, as sementes foram mantidas sobre papel-filtro em ambiente com circulação de ar por 24 horas. Posteriormente, foram armazenadas em sacos plásticos colocados dentro de tambores de papel Kraft, permanecendo em câmara fria do laboratório, com temperatura de $\pm 10^{\circ} \mathrm{C}$ e umidade relativa em torno de $80 \%$, durante 14 dias.

No $15^{\circ}$ dia após a coleta foi determinado, segundo as recomendações das Regras para Análise de Sementes (BRASIL, 2009), o Peso de Mil Sementes utilizando oito repetições de 100 
sementes, o Número de Sementes por Quilograma e o Teor de Água, determinado pelo método de estufa a $105 \pm 3{ }^{\circ} \mathrm{C}$, por 24 horas com seis repetições de cinquenta sementes.

A Condutividade Elétrica (CE) foi avaliada pelo método de massa, com quatro repetições de 25 sementes imersas em $75 \mathrm{~mL}$ de água destilada, por um tempo de embebição de 24 horas (PIÑARODRIGUES et al., 2004). Inicialmente, as sementes foram pesadas em balança eletrônica, com precisão de $0,001 \mathrm{~g}$ e, posteriormente, incubadas em câmara do tipo BOD, à temperatura de $25^{\circ} \mathrm{C}$. Após o período de embebição, a CE foi medida utilizando o condutivímetro Quimis ${ }^{\circledR}$, sendo que os resultados foram expressos em $\mu \mathrm{S} \mathrm{cm}^{-1} \mathrm{~g}^{-1}$.

O Teste de Germinação em laboratório foi conduzido em delineamento experimental inteiramente casualizado, com sete tratamentos (substratos) e quatro repetições, com vinte e cinco sementes cada. Os recipientes utilizados foram caixas plásticas transparentes com tampa, do tipo gerbox, sendo avaliados os seguintes substratos: sobre papel mata-borrão (PMB) e sobre papelfiltro (SPF) (2 folhas umedecidas com 2,5 vezes o peso do papel), sobre (SA) e entre areia (EA) (fina e peneirada, com malha de $0,84 \mathrm{~mm}, 324 \mathrm{~g}$ de areia autoclavada e umedecida com $62 \mathrm{~mL}$ de água destilada), sobre (SV) e entre vermiculita (EV) (granulometria fina, $24 \mathrm{~g}$ de vermiculita autoclavada e umedecida com $83 \mathrm{~mL}$ de água destilada) e rolo de papel (RP) ( 3 folhas umedecidas com 2,5 vezes o peso do papel, colocadas dentro de saco plástico).

Para areia e vermiculita foi acrescentado um volume de água para $100 \%$ da capacidade de campo, ambos substratos foram esterilizados em autoclave a $120^{\circ} \mathrm{C}$ por 2 horas, e os gerbox esterilizados com formol em estufa a $50{ }^{\circ} \mathrm{C}$ por 48 horas.

As sementes foram pré-condicionadas em solução de $100 \mathrm{~mL}$ de água destilada com 6 gotas de detergente neutro, ficando submersas durante 5 minutos e depois enxaguadas duas vezes em água destilada, permanecendo por três minutos no último enxágue. Os gerbox com as sementes foram colocados em câmara de germinação do tipo Mangelsdorf, com luz constante e temperatura de $25 \pm 2{ }^{\circ} \mathrm{C}$.

As contagens foram realizadas a cada três dias, a partir da instalação do teste até seu encerramento, que ocorreu aos 30 dias. Considerouse germinadas as sementes que apresentaram todas as estruturas essenciais (raiz primária, hipocótilo, epicótilo, cotilédones e protófilos), representando plântulas normais, além da percentagem de plântulas anormais, sementes firmes (aparentemente viáveis, mas que não germinaram) e mortas, segundo definição de BRASIL (2009) e, de forma complementar, foi calculado o índice de velocidade de germinação (IVG), conforme Maguire (1962).

Para a análise estatística considerou-se, anteriormente à realização da análise de variância, se os dados das variáveis analisadas atendiam às pressuposições básicas de normalidade e homocedasticidade (SANTANA e RANAL, 2004). Foram utilizados os testes de Shapiro-Wilk para verificar a normalidade dos resíduos e de Bartlett para homogeneidade entre as variâncias. Quando essas pressuposições não foram atendidas, procedeu-se a transformação dos dados através do $\operatorname{arcsen}(\mathrm{x} / 100)^{0,5}$. As variáveis plântulas anormais, sementes firmes e mortas não atingiram a normalidade dos resíduos com a transformação e, portanto, foi utilizado teste não paramétrico de Kruskal-Wallis. Nas demais comparações, após a análise de variância, para as variáveis plântulas normais e IVG, foi utilizado o teste de Tukey, a $5 \%$ de probabilidade de erro. As médias apresentadas nas tabelas correspondem aos dados não transformados.

\section{RESULTADOS E DISCUSSÃO}

O lote de sementes utilizado no estudo apresentou Peso de Mil Sementes de 45,5 g (CV $2,78 \%$ ), Teor de Água de 26,5\% (CV 2,88\%), 21.973 sementes $/ \mathrm{Kg}$ e Condutividade Elétrica de $0,85 \mu \mathrm{S} \mathrm{cm}^{-1} \mathrm{~g}^{-1}$. Seneme et al. (2006), estudando sementes de Allophylus edulis, observaram Teor de Água expressivamente menor (6,5\%), apesar do maior peso obtido para mil sementes $(50,9 \mathrm{~g})$, o que sugere variação de tamanho nas sementes em diferentes regiões de coleta. Abreu (2002) constatou, para sementes desta espécie, um Teor de Água de $30,8 \%$ e número de sementes por quilograma de 18.438. A variação do tamanho das sementes pode ser advinda das condições ambientais nas quais se desenvolvem, qualidade do solo, disponibilidade de água, luz, fatores genéticos e posição do fruto na planta (FENNER e THOMPSON, 2005).

$\mathrm{O}$ início da germinação das sementes de Allophylis edulis ocorreu no nono dia após a semeadura. O substrato EV apresentou a maior percentagem de sementes germinadas (plântulas normais) durante todo o teste ( $93 \%$ aos 24 dias) (Figura 1), apesar de, estatisticamente, não ter 
apresentado diferença em relação ao PMB, SPF, $\mathrm{SA}, \mathrm{SV}$ e RL, mas diferenciando apenas do EA. Isso pode ser explicado pelo fato de comumente, se observar em laboratório, que a vermiculita perde água mais facilmente que a areia. Além disso, o fato de a areia ter sido umedecida até $100 \%$ da capacidade de campo pode ter reduzido a oxigenação, necessária em níveis adequados para a germinação. Segundo Higashi et al. (2002) a areia fina, embora apresente capacidade de retenção de água semelhante à vermiculita, possui menor porosidade de aeração.

Apesar de avaliações terem sido efetuadas até o $30^{\circ}$ dia após a instalação do teste, a maioria dos tratamentos poderia ter sido encerrada no $24^{\circ}$ dia. Abreu et al. (2005) caracterizaram a germinação de Allophylus edulis, a qual foi conduzida em rolo de papel sob temperatura de $25{ }^{\circ} \mathrm{C}$ e presença de luz contínua, observaram que a germinação das sementes teve início no oitavo dia, podendo ser encerrada no $15^{\circ}$ dia após a semeadura.

Wielewicki et al. (2006) propuseram padrões de germinação e teor de água para algumas espécies florestais da região sul do Brasil. Nesse trabalho, o substrato indicado para o teste de germinação foi o "sobre papel" e a duração do teste foi de 23 dias. As médias da germinação e do teor de água dos lotes avaliados foram de $87,4 \% \mathrm{e}$ $19,8 \%$, respectivamente. Os autores apresentaram como proposta para o teste de germinação contagem final aos 27 dias, com $79 \%$ de germinação e teor de água das sementes de $28,1 \%$. No presente trabalho, os valores verificados nos melhores tratamentos estão adequados à proposta desses autores.

Por outro lado, visando acelerar o tempo de condução do teste e reduzir a proliferação de patógenos, o uso de SPF ou PMB, que também apresentaram boas respostas de germinação, representaram necessidade de maior tempo para a conclusão do teste, conforme o IVG. As avaliações de EV, SV, SA e RP proporcionaram maior rapidez de execução do teste, enquanto que o EA apresentou o menor valor de IVG $(0,68)$ (Tabela 1$)$.

Os substratos EA, RP e PMB aumentaram a incidência de sementes firmes comparados aos demais. Para o primeiro, isto pode ter ocorrido devido a menor incidência luminosa nas sementes e, além disso, pelo fato dessa espécie não apresentar

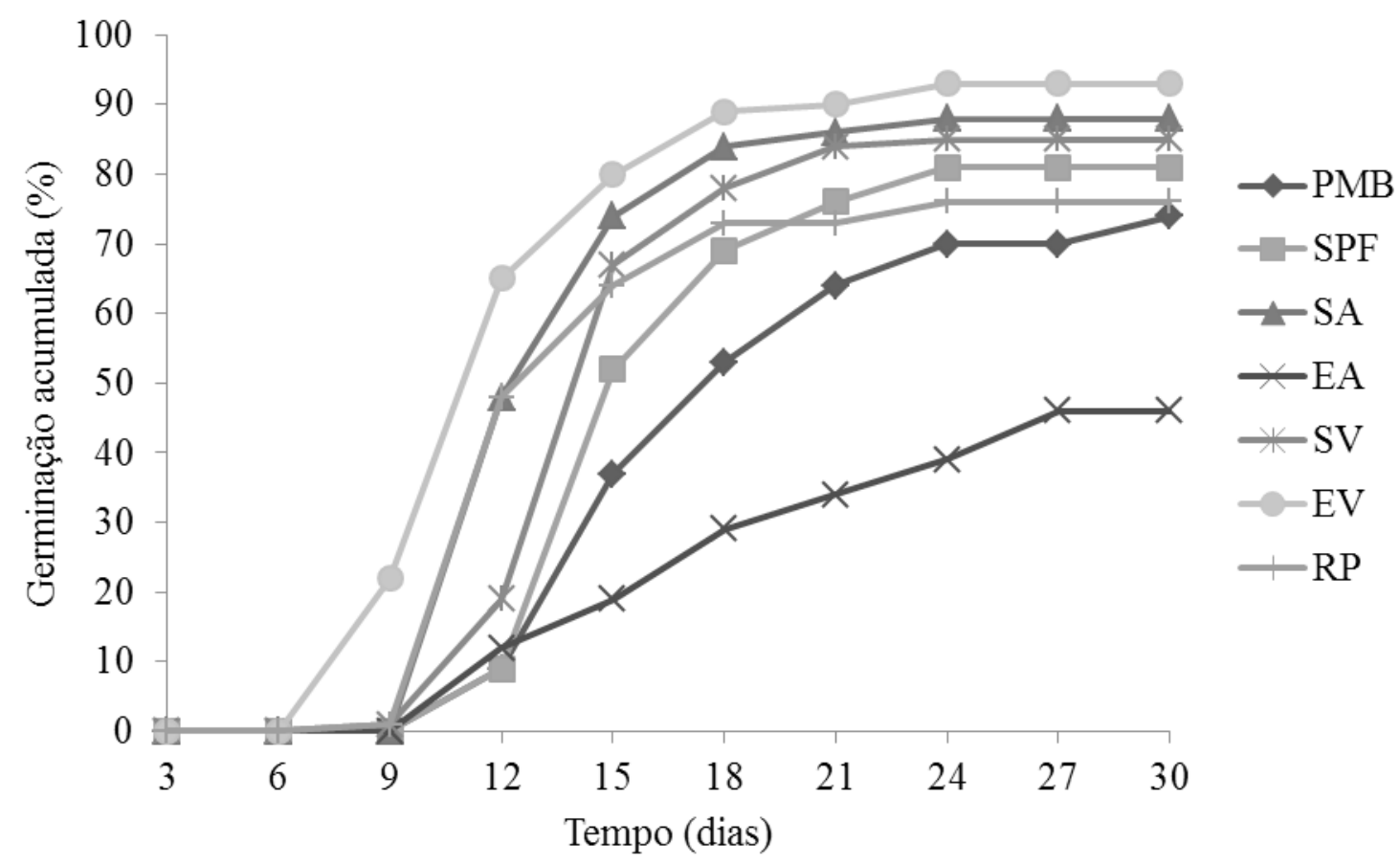

FIGURA 1: Percentagem acumulada da germinação de sementes de Allophylus edulis em diferentes substratos (PMB - sobre papel mata-borrão, SPF - sobre papel-filtro, SA - sobre areia, EA entre areia, SV - sobre vermiculita, EV - entre vermiculita e RP - rolo de papel).

FIGURE 1: Cumulative percentage of germination of Allophylus edulis seeds in different substrates (PMB - on blotting paper, SPF - on filter paper, SA - on sand, EA - among sand, SV - on vermiculite, $\mathrm{EV}$ - among vermiculite and RP - paper roll). 
TABELA 1: Influência de diferentes substratos na germinação e índice de velocidade de germinação (IVG) de sementes de Allophylus edulis (EV - entre vermiculita, SA - sobre areia, SV - sobre vermiculita, SPF - sobre papel-filtro, RP - rolo de papel, PMB - sobre papel mata-borrão e EA - entre areia).

TABLE 1: Influence of different substrates on germination and speed of germination index (IVG) of seeds of Allophylus edulis seeds (EV - among vermiculite, SA - on sand, SV - on vermiculite, $\mathrm{SPF}$ - on filter paper, RP - paper roll, PMB - on blotting paper and EA - among sand).

\begin{tabular}{|c|c|c|c|c|c|}
\hline Tratamentos & $\begin{array}{c}\text { Plântulas } \\
\text { Normais }(\%)^{\mathrm{A}}\end{array}$ & $\mathrm{IVG}^{\mathrm{A}}$ & $\begin{array}{c}\text { Plântulas Anormais } \\
(\%)^{\mathrm{B}}\end{array}$ & $\begin{array}{c}\text { Sementes Mortas } \\
(\%)^{\mathrm{B}}\end{array}$ & $\begin{array}{c}\text { Sementes Firmes } \\
(\%)^{\mathrm{B}}\end{array}$ \\
\hline EV & $93 \mathrm{a}$ & $1,93 \mathrm{a}$ & $2 \mathrm{a}$ & $1 \mathrm{~b}$ & $4 \mathrm{a}$ \\
\hline SA & $88 \mathrm{a}$ & $1,62 \mathrm{ab}$ & $3 \mathrm{a}$ & $0 \mathrm{a}$ & $9 \mathrm{a}$ \\
\hline SV & $85 \mathrm{a}$ & $1,44 \mathrm{ab}$ & $4 \mathrm{~b}$ & $0 \mathrm{a}$ & $11 \mathrm{a}$ \\
\hline SPF & $81 \mathrm{a}$ & $1,28 \mathrm{bc}$ & $14 \mathrm{~b}$ & $0 \mathrm{a}$ & $5 \mathrm{a}$ \\
\hline $\mathrm{RP}$ & $76 \mathrm{a}$ & $1,43 \mathrm{ab}$ & $1 \mathrm{a}$ & $2 \mathrm{~b}$ & $21 \mathrm{~b}$ \\
\hline PMB & $74 \mathrm{a}$ & $1,10 \mathrm{bc}$ & $11 \mathrm{~b}$ & $2 b$ & $13 \mathrm{~b}$ \\
\hline EA & $46 \mathrm{~b}$ & $0,68 \mathrm{c}$ & $2 \mathrm{a}$ & $1 \mathrm{~b}$ & $51 \mathrm{~b}$ \\
\hline $\begin{array}{l}\text { Pressuposições } \\
\text { Básicas } W^{1}\end{array}$ & $\operatorname{Pr}<W 0,962$ & $\operatorname{Pr}<W 0,936$ & $\operatorname{Pr}<W$ 0,0001/0,0007 & $\operatorname{Pr}<W$ 0,0001/0,0001 & $\operatorname{Pr}<W$ 0,0001/0,0084 \\
\hline$\chi^{2}$ & $\begin{array}{c}\text { Alpha } \\
0,180\end{array}$ & $\begin{array}{c}\text { Alpha } \\
\mathbf{0 , 2 5 1}\end{array}$ & $\begin{array}{l}\text { Alpha } \\
0,0461\end{array}$ & $\begin{array}{c}\text { Alpha } \\
\mathbf{0 , 2 7 8 6 / 0 , 0 0 0 0}\end{array}$ & $\begin{array}{c}\text { Alpha } \\
\mathbf{0 , 0 0 2 7 / 0 , 0 7 3 6}\end{array}$ \\
\hline C.V. $(\%)$ & 19,25 & 14,48 & 86,61 & 225,89 & 40,40 \\
\hline
\end{tabular}

Em que: $\mathrm{W}^{1}$ : estatística do teste de Shapiro-Wilk e $\chi^{2}$ : estatística do teste de Bartlett. Valores em negrito indicam normalidade dos resíduos e homogeneidade da variância, respectivamente, após transformação dos dados. As médias seguidas da mesma letra na coluna não diferem entre si pelo teste de Tukey ${ }^{\mathrm{A}}$ e Kruskal-Wallis ${ }^{\mathrm{B}}$ a $5 \%$ de probabilidade de erro.

aumento expressivo do tamanho da semente quando absorve água. A caracterização de semente firme pode ter sido confundida por condição de quiescência das sementes, que não germinam por falta de condições adequadas, no caso, falta de oxigênio.

O substrato EA, normalmente é recomendado para sementes grandes, não exigentes à luz, de germinação lenta e sensíveis ao ressecamento (FIGLIOLIA et al. 1993). Os mesmos autores relataram que este substrato pode apresentar problema de desuniformidade na capacidade de retenção, bem como a água que fica depositada na parte inferior do recipiente pode prejudicar o desenvolvimento da plântula.

Os substratos SPF, PMB e SV apresentaram os maiores percentuais de sementes com anormalidades, sendo que as mais frequentes foram necrose da radícula e do hipocótilo e também, a má-formação dos mesmos, que, nesse caso, pode ter ocorrido em virtude da perda de umidade do substrato, prejudicando o desenvolvimento das plântulas.

\section{CONCLUSÕES}

Os substratos sobre areia e entre vermiculita são os mais adequados para a condução do teste de germinação de Allophylus edulis, sendo que a primeira contagem pode ser realizada entre 12 e 15 dias e a contagem final aos 24 dias após a semeadura.

\section{REFERÊNCIAS BIBLIOGRÁFICAS}

ABREU, D. C. A. Caracterização morfológica de frutos e sementes e germinação de Allophylus edulis (St.Hil.) Radlk e Drymis brasiliensis Miers. 2002. 91 f. Dissertação (Mestrado em Ciências Florestais) - Universidade Federal do Paraná, Curitiba, 2002.

ABREU, D. C. A. et al. Caracterização morfológica de frutos, sementes e germinação de Allophylus edulis (St.-Hill) Radlk. (Sapindaceae). Revista Brasileira de Sementes, Pelotas, v. 27, n. 2, p. 5966, dez. 2005.

BACKES, A.; NARDINO, M. Árvores, arbustos e algumas lianas nativas do Rio Grande do Sul. 
São Leopoldo: Unisinos, 1998. 202 p.

BRASIL, Ministério da Agricultura, Pecuária e Abastecimento. Regras para análise de sementes. Secretaria de Defesa Agropecuária. Brasília: Mapa/ ACS, 2009. 399 p.

CARVALHO, P. E. R. Espécies Arbóreas Brasileiras. Colombo: Embrapa Informação Tecnológica: Embrapa Florestas, 2006. 627 p. v. 2. COPELAND, L. O; MCDONALD, M. B. Seed science and technology. 3rd ed. New York: Chapman \& Hall, 1995. 409 p.

CUNHA, A. O. et al. Efeitos de substratos e das dimensões dos recipientes na qualidade das mudas de Tabebuia impetiginosa (Mart. Ex D.C.) Standl. Revista Árvore, Viçosa, v. 29, n. 4, p. 507-516, jul./ ago. 2005.

FENNER, M.; THOMPSON, K. The ecology of seeds. Cambridge: Cambridge University Press, 2005. $250 \mathrm{p}$.

FIGLIOLIA, M. B.; OLIVEIRA, E. C.; PIÑARODRIGUES, F. C. M. Análise de sementes. In: AGUIAR, I. B.; PIÑA-RODRIGUES, F. C. M.; FIGLIOLIA, M. B. Sementes florestais tropicais. Brasília: Abrates, 1993. cap. 4, p. 137-174.

HIGASHI, E. N.; SILVEIRA, R. L. V. A.; GONÇALVES, A. N. Nutrição e adubação em minijardim clonal hidropônico de Eucalyptus. Circular Técnica IPEF, Piracicaba, n. 194, p. 1-21, jan. 2002.

LABOURIAU, L. G. A germinação das sementes.

Washington: OEA-Programa Regional de Desenvolvimento Científico e Tecnológico, 1983.
$174 \mathrm{p}$.

LONGHI, R. A. Livro das árvores: árvores e arvoretas do Sul. Porto Alegre: L\&PM, 1995. 176 p. LORENZI, H. Árvores brasileiras: manual de identificação e cultivo de plantas arbóreas do Brasil. Nova Odessa: Plantarum, 1998. 352 p. v.1.

MAGUIRE, J. B. Speed of germination-aid in selection and evaluation for seedling emergence vigor. Crop Science, Madison, v. 2, n. 2, p.176-177, 1962.

OLIVEIRA, O. S. Tecnologia de sementes florestais. Curitiba: Imprensa Universitária, 2007. $185 \mathrm{p}$.

PINÃ-RODRIGUES, F. C. M.; FIGLIOLIA, M. B.; PEIXOTO, M. C. Testes de qualidade. In: FERREIRA, A. G.; BORGHETTI, F. (Orgs.).

Germinação: do básico ao aplicado. Porto Alegre: Artmed, 2004. cap. 11, p. 283-295.

SANTANA, D. G.; RANAL, M. A. Análise da germinação: um enfoque estatístico. Brasília: Ed. Universidade de Brasília, 2004. 248 p.

SCHMIDT, L. Tropical Forest Seed. New York: Springer, 2007. 409 p.

SENEME, A. M.; POSSAMAI, E.; SCHUTA, L. R. Germinação e sanidade de sementes de vacum (Allophylus edulis). Revista Ceres, Viçosa, v.53, n. 305, p.1-6, jan./fev. 2006.

WIELEWICKI, A. P. et al. Proposta de padrões de germinação e teor de água para sementes de algumas espécies florestais presentes na região sul do Brasil. Revista Brasileira de Sementes, Pelotas, v. 28, n. 3, p. 191-197, dez. 2006. 